\title{
The Correlation of Francisella tularensis on Size and Supercooling of Dermacentor variabilis
}

\author{
Amal El Nabbout ${ }^{1}$, Brittany J. Taylor ${ }^{1}$, James Kho ${ }^{1}$, Mandy Mitton ${ }^{1} \&$ Tatiana Rossolimo ${ }^{1}$ \\ ${ }^{1}$ Department of Biology, Dalhousie University, 1355 Oxford Street, Halifax, Nova Scotia, B3H 4R2, Canada \\ Correspondence: Amal El Nabbout, Department of Biology, Dalhousie University, 1355 Oxford Street, Halifax, \\ Nova Scotia, B3H 4R2, Canada. E-mail: amalnabbout@hotmail.com
}

Received: January 8, 2018

Accepted: January 19, 2018

Online Published: March 3, 2018

doi:10.5539/ijb.v10n2p15

URL: https://doi.org/10.5539/ijb.v10n2p15

\begin{abstract}
Overwintering tick survival is essential for the continuation of a tick's lifecycle. Recent studies have found that infections with particular microorganisms can alter the physiology of ticks and, in some cases, increase their cold hardiness. To date, the influence of Francisella tularensis on Dermacentor variabilis (Say) has not been studied and thus the symbiosis between the two has been unknown. This study determined the infection rate of $F$. tularensis as well as examined the relationship between $F$. tularensis and the supercooling point (SCP) and size of D. variabilis of ticks from Nova Scotia, Canada. Local veterinarians provided adult ticks. The SCP of each tick was recorded using Logger Pro and infection status was found using Polymerase Chain Reaction. Of the 203 ticks tested, $9.8 \%$ were infected with $F$. tularensis. When the sexes were considered separately, $4 \%$ of males, $11.7 \%$ engorged females and $17.3 \%$ of non-engorged females were infected. Upon further analysis, a statistically significant difference was found between infected ticks and changes in thier SCPs, but there was no statistically significant difference between infected ticks and changes in size. This suggests that $F$. tularensis benefits $D$. variabilis by decreasing their SCPs, and thereby enhancing their overwintering capabilities. While other physiological influences of $F$. tularensis on $D$. variabilis remain unknown, the results from this study support previous research that bacterium species such as $F$. tularensis is able to influence the survivability of its tick host in the form of altering their freezing tolerance but does not affect the physical size of $D$. variabilis.
\end{abstract}

Keywords: Tick-borne diseases, ticks, tularemia, cold hardiness, infection rate, tick symbiosis, etymology, parasitology

\section{Introduction}

\subsection{Dermacentor Variabilis and Francisella Tularensis}

Francisella tularensis (Dorofe'ev, 1947), is a highly infectious, non-motile, non-spore forming, aerobic, gram-negative coccobacillus bacteria. These bacteria have many routes of infection, including handling of infected animals (especially rabbits), consumption of contaminated food or water, inhalation of infective aerosols (as in biological weaponry) and through arthropod bites (Dennis et al., 2001; Hayes et al., 2005; Petersen \& Schriefer, 2005; WHO, 2017; Peterson et al., 2008). It is important to study F. tularensis because it is the causative agent of tularemia, a disease in both humans and animals (Dennis et al., 2001; WHO, 2017 Peterson et al., 2008). Within the scope of tick bites, there are two disease phenotypes of tularemia: ulceroglandular tularemia and glandular tularemia, both of which are potentially detrimental infections if left untreated due to secondary complications such as meningitis and skin suppuration (Dennis et al., 2001; WHO, 2017; Peterson et al., 2008).

Francisella tularensis has been identified in at least 13 species of ticks found east of the Rocky Mountains, representing four genera: Amblyomma, Dermacentor, Haemaphysalis, and Ixodes (Hopla, 1974). Within these groups, Dermacentor variabilis Say 1821 is thought to be one of the most important species for transmitting $F$. tularensis to humans and animals living in the Northern hemisphere (Reese et al., 2010). In addition to transmission, ticks also act as reservoir hosts in which $F$. tularensis within their gut, hemolymph or ovaries can persist for long periods of time (Petrov, 1960; Hopla, 1974; WHO, 2017; Genchi, 2015).

\subsection{Overwintering Tick Survival}

It is essential for ticks to have strategies which will mitigate the detrimental effects of sub-zero temperatures in order to continue their life cycles ( $\mathrm{Yu}$ et al., 2014). Freeze avoidance is the main strategy used by arthropods. 
Freeze avoidance includes a number of strategies including adaptive responses, biochemical alterations and physiological changes which aid in preventing freezing (Doucet et al., 2009; Bale, 2002). Freeze avoidance involves altering the contents in the body as well as accumulating cryoprotectants such as glycerol, sorbitol, and other low-molecular-weight polyols and sugar which aid in the prevention of crystal formation (Lee et al., 1987). Since ticks are not freeze-tolerant, adaptations that prevent crystallization is essential for tick survival (Burks et al., 1996; Dautel \& Knülle, 1996, 1997, 1998; Needham et al., 1996; Stark \& Gothe, 2000; Lee, 2010).

\subsection{Microbial Symbiotic Relationships}

As current research suggests, pathogen-vector relationships can be parasitic, commensal, or mutualistic in ticks (Carmichael \& Fuerst, 2006; Herrmann \& Gern, 2010; Neelankanta et al., 2010; Herrmann et al., 2013, Nabbout et al., 2017). Despite all this research, not much is known about how microbes influence the physiology of ticks during cold exposure. Neelakanta et al. (2010) was the first to find that infections with Anaplasma phagocytophilum Foggie 1949 in Ixodes scapularis increases the ticks' cold hardiness through the expression of an antifreeze protein. This study shows that infections with certain microorganisms can alter the SCP of ticks. Therefore, the goal of the current study was to investigate the possibility of $F$. tularensis altering the SCP of $D$. variabilis.

Currently, the influence of infection on size and SCP in other species of ticks infected with microorganisms is relatively unknown. A recent study showed that Dermacentor variabilis infected with Rickettsia spp. had the same SCP as uninfected ticks (Nabbout et al., 2017). This earlier study illustrated an example of the relationship between ticks and microorganisms having minimal effect on physiology. Both studies by Neelakanta et al. (2010) and Nabbout et al. (2017) suggest varying results with respect to the impact of microorganisms infection on its host thus it is imperative to explore the potential effects of different bacteria species infection. Focusing back to the aim of this study, Francisella tularensis is able to live within D. variabilis for long periods of time; however it is not known if $F$. tularensis harms or benefits $D$. variabilis in terms of increased size or decreased SCP (Petrov, 1960; Hopla, 1974).

\subsection{Aims of this Study}

The first aim of this study was to identify the infection rate of $F$. tularensis in D. variabilis ticks from Nova Scotia. It was hypothesized that the infection rate of $D$. variabilis would be less than $5 \%$. The second aim of this study was to determine the relationship between size and supercooling point (SCP) in D. variabilis ticks, without considering infection. It was hypothesized that males, females and engorged females would express a positive correlation with size. The final aim of this study was to see if infected ticks express a change in size or in SCP. It was hypothesized that $F$. tularensis infected ticks would have a lower SCP and a smaller size compared to uninfected ticks.

\section{Materials and Methods}

\subsection{Tick Collection}

Adult dog ticks ( $D$. variabilis) were collected from local veterinarians in the Halifax Regional Municipality from May to July and from September to October of 2014 to 2017, as well as through field collections. Upon arrival to the lab, each tick was identified as male or female (engorged or not), and then this information was recorded into a database.

\subsection{SCP Determination}

The freezing point of each tick was recorded using thermocouples (Vernier), a thermistor, a VWR International Model: 1197P cooling bath and a computer software program called Logger Pro. The cooling bath was programmed to decrease at a rate of $1{ }^{\circ} \mathrm{C}$ per minute. The medium used in the bath was ethylene glycol $70 \%$ which has a freezing point around $-50^{\circ} \mathrm{C}$ (Engineering toolbox, n.d.). Ticks were dorsally attached to the metal end of the thermocouples and thermistor using petroleum jelly (Vaseline).

\subsection{DNA Extraction}

Each tick was cut along the sagittal axis of the body. Only one-half of the tick was used for DNA extraction. The forceps, scale and scalpel were cleansed with $70 \%$ ethanol between the divisions of each tick in order to prevent cross-contamination. Homogenization was aided by adding $50 \mu \mathrm{L}$ of AquaGenomic solution. Sterilizing of equipment with $70 \%$ ethanol occurred after each homogenization. Each tick was incubated in a Precision water bath at $60^{\circ} \mathrm{C}$ for 45 minutes, vortexed for 30 seconds, and then centrifuged on high speed for 4 minutes. The supernatant was transferred into $50 \mu \mathrm{L}$ of isopropanol then centrifuged again on high speed for 4 minutes. The supernatant was decanted and rinsed with $50 \mu \mathrm{L}$ of $70 \%$ ethanol. Once dried, $50 \mu \mathrm{L}$ of nuclease free water $\left(\mathrm{ddH}_{2} 0\right)$ was added. The sample was placed in the water bath at $60^{\circ} \mathrm{C}$ for 60 minutes. After the incubation period, DNA was stored in the freezer at $-18^{\circ} \mathrm{C}$ until it was needed for PCR. 


\subsection{Polymerase Chain Reaction \& Gel Electrophoresis}

PCR was determined to be a more suitable method of assessing the presence of bacterial infection in ticks over bacteria culturing (incubation time of roughly five days per plate (Petersen et al. 2004)) especially with our sample size $(n=203)$, and initial strategy to examine the infection prevalence for all the tick samples. The target sequence for $F$. tularensis was the $17 \mathrm{kDa}$ outer membrane protein (tul4) using the primers FT393 (5'-ATG GCG AGT GAT ACT GCT TG) and FT642 (5'-GCA TCA TCA GAG CCA CCT AA). The target amplicon size was 250bp (Long et al., 1993). A master mix was made by combining nuclease free water $\mathrm{nfH} 2 \mathrm{O}(12.5 \mu \mathrm{L} / \mathrm{sample})$, GoTaq Green Master Mix 2 X $(8.5 \mu \mathrm{L} /$ sample $)$, forward primer $(1 \mu \mathrm{L} /$ sample $)$ and reverse primer $(1 \mu \mathrm{L} / \mathrm{sample})$. Each PCR tube received $23 \mu \mathrm{L}$ of the master mix and $2 \mu \mathrm{L}$ of extracted DNA. In order to test for contamination, 2 controls were used. Both controls were made by adding $23 \mu \mathrm{L}$ with $2 \mu \mathrm{L}$ nuclease free water, and negative results were expected.

The PCR amplification was conducted on a Eppendorf Mastercycler ep Gradient S. Amplification started with denaturation at $94^{\circ} \mathrm{C}$ for $3 \mathrm{~min}$, followed by denaturation at $94^{\circ} \mathrm{C}$ for $30 \mathrm{~s}$, annealing at $56^{\circ} \mathrm{C}$ for $45 \mathrm{~s}$ and extension at $72^{\circ} \mathrm{C}$ for $45 \mathrm{~s}$. During the subsequent cycles, the annealing was lowered by $1{ }^{\circ} \mathrm{C}$ until it reached $72^{\circ} \mathrm{C}$. Following the touchdown program, there were 40 repeated amplification cycles $\left(94^{\circ} \mathrm{C}\right.$ for $30 \mathrm{~s}, 56^{\circ} \mathrm{C}$ for $45 \mathrm{~s}, 72^{\circ} \mathrm{C}$ for $\left.45 \mathrm{~s}\right)$. The PCR ended with a final extension at $72^{\circ} \mathrm{C}$ for $10 \mathrm{~min}$ (Long et al., 1993).

The electrophoresis gel was made using $2 \mathrm{~g}$ of agarose, $100 \mathrm{~mL}$ of $0.5 \mathrm{x}$ concentrate Tris-Borate-EDTA (TBE) buffer, and $5 \mu \mathrm{L}$ SYBR Safe Green. A $5 \mu \mathrm{L} 100 \mathrm{bp}$ DNA ladder RTU (Ladder Gene Direx) was used and $5 \mu \mathrm{L}$ of PCR sample was added to each well. The gel ran at $100 \mathrm{~V}$ for 1 hour; then, using UV, a photo was taken (using a CANON EOS Rebel T5) for analysis.

\subsection{Statistical Analysis}

T-tests were performed on the sizes and SCPs of infected versus uninfected ticks. A Pearson's Correlation was used to find the R-value, which expressed the strength of correlation between size and SCP.

\section{Results}

\subsection{Size and SCP Correlation}

For all ticks, there was a positive correlation between size and SCP (Figure 1). Non-engorged females had the strongest correlation $(\mathrm{r}=0.08)$ followed by males $(\mathrm{r}=0.02)$, and engorged females $(\mathrm{r}=0.02)$ (Figure 1$)$. When all ticks were compared, there was a cluster of data points between $0 \mathrm{mg}$ and $20 \mathrm{mg}$ followed by a less dense cluster between $20 \mathrm{mg}$ and $40 \mathrm{mg}$ (Figure $1 \mathrm{~A}$ ). The majority of all SCPs fell between $-10^{\circ} \mathrm{C}$ and $-20^{\circ} \mathrm{C}$. For males, there was a dispersed set of data points, falling between $4 \mathrm{mg}$ and10 $\mathrm{mg}$ (Figure $1 \mathrm{~B}$ ). Non-engorged females express a cluster between $7 \mathrm{mg}$ and $10 \mathrm{mg}$, and engorged females express a cluster between $20 \mathrm{mg}$ and $40 \mathrm{mg}$ (Figure $1 \mathrm{C} \mathrm{\&} \mathrm{D)}$. Both engorged and non-engorged females did not have a high concentration of points near a particular area compared to males. All correlations were found to be positive.

\subsection{Infection Rates}

From the 203 samples of D. variabilis adults, $9.8 \%(\mathrm{n}=20 / 203)$ were infected with $F$. tularensis. Out of each sample set, non-engorged females showed the highest infection rate at $17.3 \%(\mathrm{n}=9 / 52)$. Males have a $5 \%$ infection rate $(\mathrm{n}=5 / 100)$ and engorged females $11.7 \%(\mathrm{n}=6 / 51)$.

\subsection{Infection and Size}

Mean tick body size of $D$. variabilis adults sampled in 2014 to 2017 were $7.49 \mathrm{mg} \pm 1.8$ for males ( $\mathrm{n}=100$; range $1.17 \mathrm{mg}-11.4 \mathrm{mg}$ ), $8.3 \mathrm{~g} \pm 3.0$ for non-engorged females $(\mathrm{n}=52$; range $1.5 \mathrm{mg}-19.0 \mathrm{mg}$ ), and $34.8 \mathrm{mg} \pm 9.4$ for engorged females $(\mathrm{n}=51$; range $14.0 \mathrm{mg}-86.9 \mathrm{mg})$. The mean and median tick body size of non-infected $D$. variabilis adults sampled in 2014 to 2017 were $7.5 \mathrm{mg} \pm 1.8$ for males, $8.4 \mathrm{~g} \pm 3.3$ for non-engorged females and $34.8 \mathrm{mg} \pm 9.8$ for engorged females (Table 1). Infected ticks' average weights were $7.2 \mathrm{mg} \pm 0.57$ for males, $7.9 \mathrm{mg}$ \pm 0.7 for non-engorged females, and $34.8 \mathrm{mg} \pm 5.4$ for infected engorged females (Figure 2). There was no significant difference between males $(\mathrm{P}=0.64)$, females $(\mathrm{P}=0.66)$, and engorged females $(\mathrm{P}=0.7)$. 
A

Weight (mg)

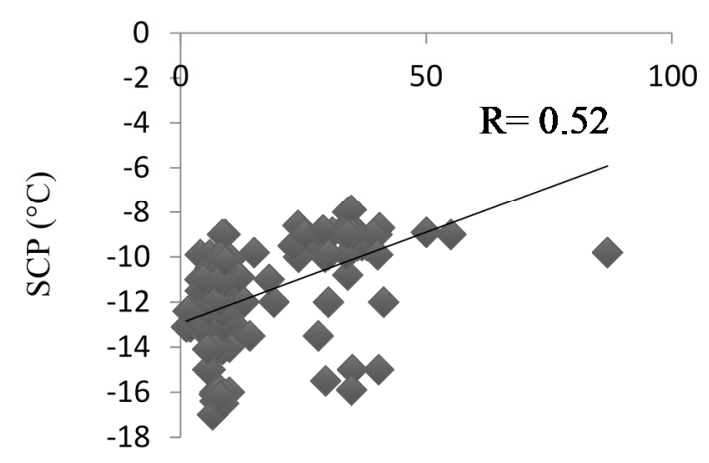

C

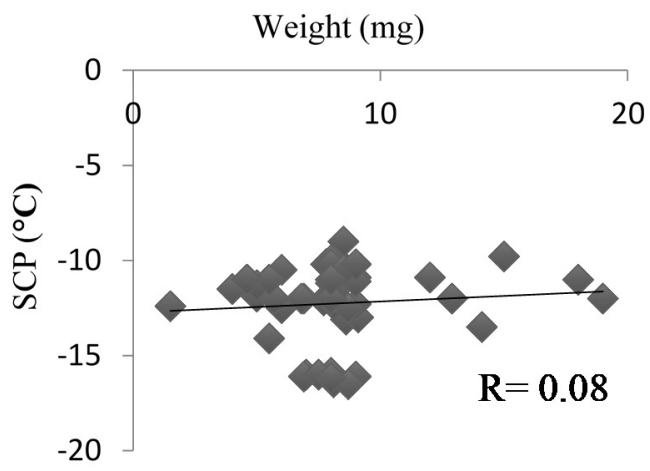

B

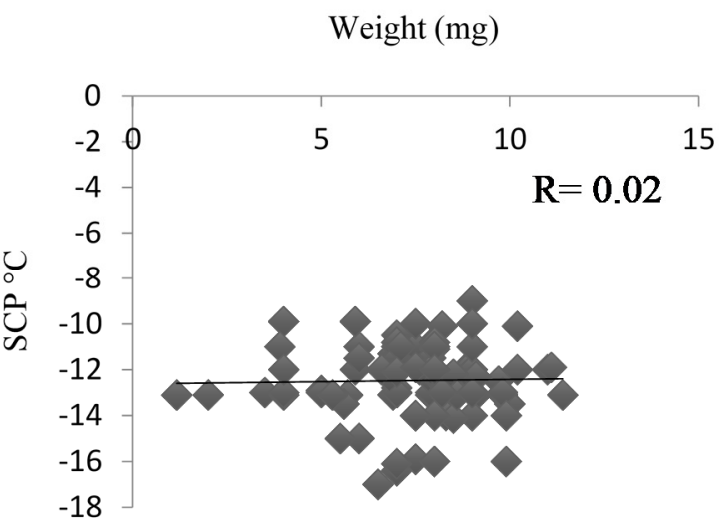

D

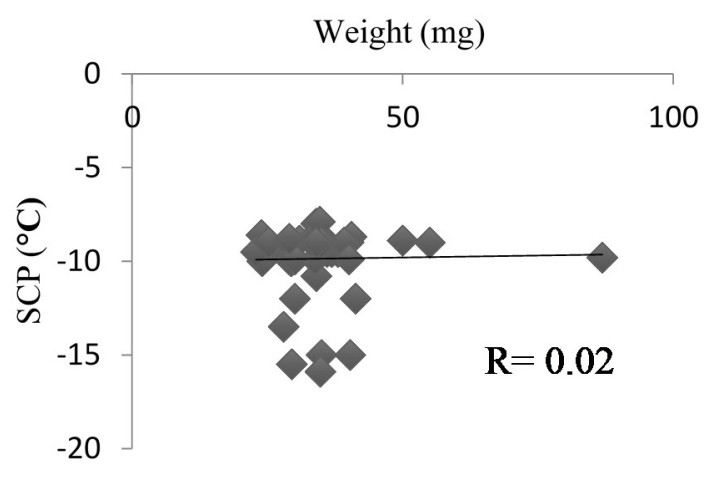

Figure 1. The relationship between weight and SCP for all Dermacentor variabilis ticks (A), only males (B), non-engorged females (C), and engorged females (D), without considering infection. A Pearson's correlation $\mathrm{R}$-value shows the strength of correlation in each group

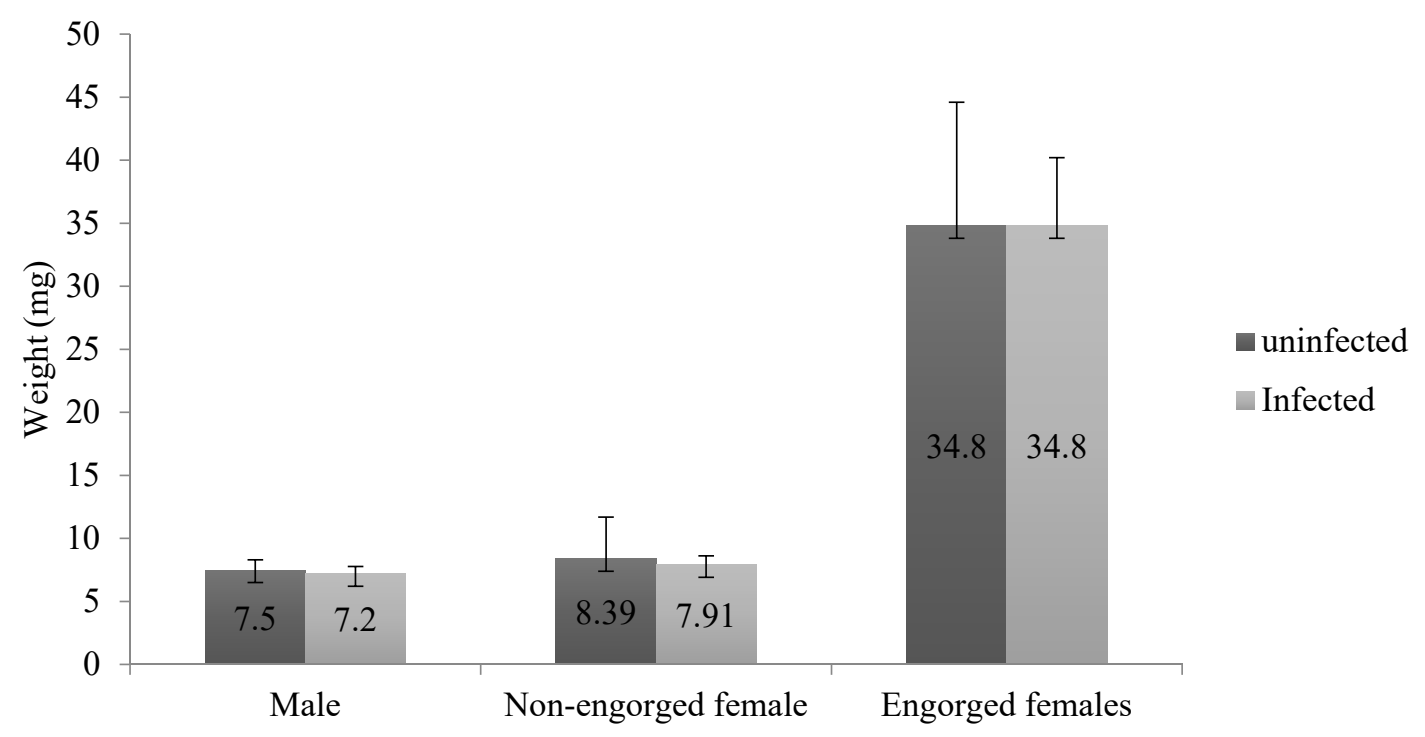

Figure 2. Mean (+LS) weight of infected and uninfected Dermacentor variabilis in male, non-engorged female and engorged female adult ticks $(n=203)$. Difference between infected and uninfected tick weights was not statistically significant 
Table 1. Mean weights and standard deviations (Stdev) of Dermacentor variabilis adult ticks collected in 2014-2017

\begin{tabular}{llll}
\hline & Male & Non-engorged female & Engorged Female \\
\hline Actual mean weight & 7.49 & 8.3 & 34.8 \\
SD & 1.8 & 3.0 & 9.4 \\
Uninfected mean weight & 7.5 & 8.4 & 34.8 \\
SD & 1.8 & 3.3 & 9.8 \\
Infected mean weight & 7.2 & 7.9 & 34.8 \\
SD & 0.57 & 0.7 & 5.4 \\
\hline
\end{tabular}

\subsection{Infection and SCP}

Mean SCPs were as follows: $-12.5^{\circ} \mathrm{C} \pm 1.48^{\circ} \mathrm{C}$ for males, $-12.2^{\circ} \mathrm{C} \pm 2.0$ for non-engorged females, and $-9.9^{\circ} \mathrm{C} \pm$ $1.8^{\circ} \mathrm{C}$ for engorged females. Infected ticks average SCPs were $-16.3^{\circ} \mathrm{C} \pm 0.4^{\circ} \mathrm{C}$ for males, $-16.1^{\circ} \mathrm{C} \pm 0.2^{\circ} \mathrm{C}$ for non-engorged females and $-14.5^{\circ} \mathrm{C} \pm 1.46$ for engorged females (Figure 3). The SCP of infected ticks regardless of sex was higher than non-infected ticks; therefore, there was a statistical difference between infected and uninfected ticks ( males $\mathrm{p}=1.88 \mathrm{E}-07$, non-engorged females $\mathrm{p}=3.6 \mathrm{E}-31$, and engorged females $\mathrm{p}=2.5 \mathrm{E}-3$ ).

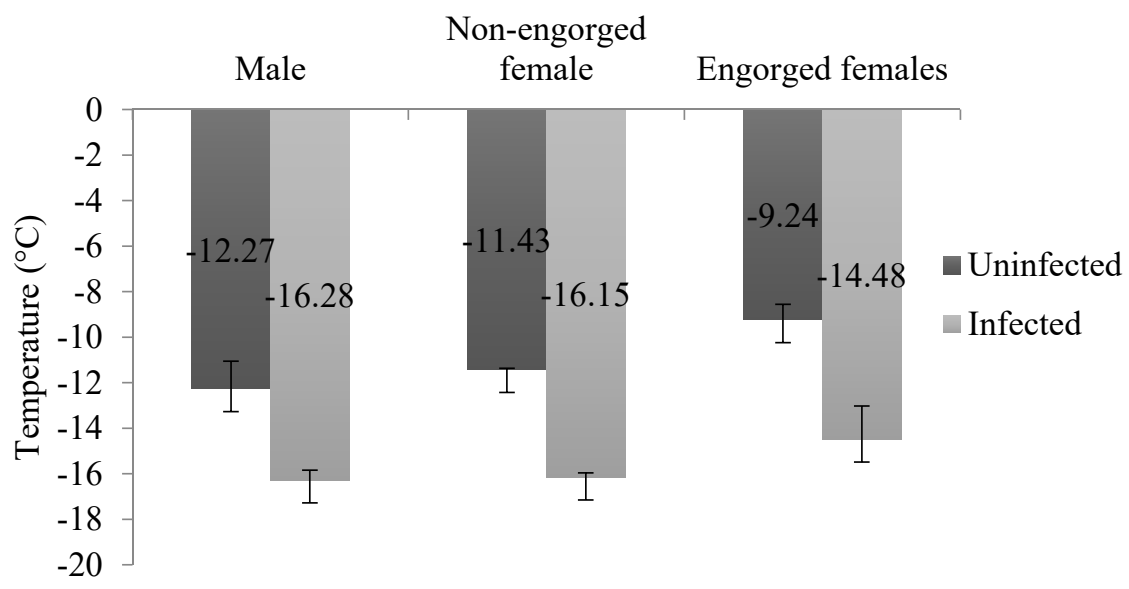

Figure 3. Mean $( \pm \mathrm{SD}) \mathrm{SCP}$ of infected and uninfected Dermacentor variabilis in male, non-engorged female, and engorged female adult ticks $(n=203)$. There was a statistically significant difference in SCP between infected and uninfected ticks

\section{Discussion}

\subsection{Size and SCP Correlation}

The positive correlation between size and SCP in males, females and engorged females shows that the larger the tick, the higher the SCP. This correlation, however, is not strong. These results match the initial hypothesis which was based on the study by Yu et al. (2014), whereby the authors proposed that the smaller the tick, the lower the SCP. Dantel and Knülle (1996) found that there was a weak negative correlation between body mass and the SCP point. In comparison, the data from this study represented the ticks in Eastern Canada and specifically Nova Scotia, a system that has not been studied previously.

The differences in the strength of correlation between the sexes suggest that temperature may affect each sex differently. Males had the strongest correlation, followed by non-engorged females, and then engorged females. It is probable that males, females and engorged females differ in their ability to reduce water content and increase cryoprotectants. Hypothetically, smaller ticks would have less water in their body compared to a larger one. This would lead to a higher concentration of cryoprotectants thus a lower SPC. In contrast, the fitness of an organism results from a balance between survival, reproductive success and fecundity (Pincheira-Donoso \& Hunt, 2015). Due to different lifestyles, there are likely different selective pressures on males, females and engorged females based on differences in fitness. The variances between each sex could account for the differences that are expressed in the strengths of correlations. Decreasing size may aid in lowering the SCP. However, size does not 
appear to be strongly correlated with SCP, as seen by the results (Figure 1). Other factors, such as body water content, are more likely have a stronger influence on the SCP and should be investigated in follow-up studies.

\subsection{Infection Rate Differences}

The overall rate of ticks infected with $F$. tularensis in Nova Scotia is low, which is beneficial in terms of human, pet, and livestock health. The infection rate $(9.8 \%)$ was higher than the hypothesized rate $(<5 \%)$ which was based on the low prevalence of $F$. tularensis in other tick species. The first study by Olsufiev \& Khatenever (1947) found I. ricinus ticks have an infection rate of $0.01 \%$ and Hubalek et al. (1997) found D. reticulatus ticks to have an infection prevalence of $2 \%$. Dermacentor variabilis ticks have a reputation for harbouring and transmitting $F$. tularensis (WHO, 2017; Reese et al., 2010); therefore, it is probable that $F$. tularensis survive better in $D$. variabilis compared to $D$. reticulatus and $I$. ricinus thus explaining the higher infection rate.

The prevalence data gained in this study is notable because it provides an assessment on the infection rate of $F$. tularensis in Atlantic Canada, specifically Nova Scotia. The results from this study suggest that there are differences in infections amongst males, females and engorged females, and future studies on ticks should take sexual differences into account when testing for infections of other bacteria. Overall, non-engorged females had the highest infection rate, compared to males. These results suggest that the female body provides a more suitable environment for $F$. tularensis compared to males. However, this trend is only present in non-engorged females.

The immune system, as well as the suitability of a tick's body, is the most probable intrinsic factors that affected the survival of $F$. tularensis. Genchi et al. (2015) found that $F$. tularensis in females resided mainly in ovaries of a different species of tick Dermacentor reticulatus. However, before the eggs were laid, the bacterium dies. The death of the bacteria observed in the study by Genchi et al. (2015) is likely due to the upregulation of the tick's innate immunity, which uses a combination of the humoral and cellular immune responses (Hajdušek et al., 2013). In contrast, our results do not suggest that the bacteria die before the eggs are laid. Instead, there is a higher infection rate in engorged females. It is possible that $F$. tularensis is tolerated in D. variabilis females even until egg production begins. F. tularensis could be indifferent to antimicrobials.

The tick gut is a hostile environment for ingested microbes, due to a higher activity of antimicrobials (Kopácek et al., 2015). This may explain why there is a difference between the infection rates of $F$. tularensis in males and females. The study by Genchi et al. (2015) did not examine males, so it is unknown as to where the bacteria reside in the male's body so our speculations to explain the male infection rate is limited. There are two postulated possibilities as to why infection rates in males are low: (1) if the bacteria need the ovaries to survive, males would naturally have a lower infection rate due to the fact that they lack these organs and (2) if $F$. tularensis survival rate is lower in other areas where they have been found, such as the hostile gut environment or the hemolymph, the infection rate in males would be lower.

\subsection{Infection Influence on SCP}

The cold-hardiness of Ixodid ticks has previously been studied, but only one study has found that microbes can influence ticks during cold exposure (Lee et al., 1987; Burks et al., 1996; Dautel \& Knulle, 1996; Neelakanta et al., 2010, Curry et al., 2017, Nabbout et al., 2017). A. phagocytophilum is the only other bacterium which has been found to increase the cold hardiness of infected ticks, thereby increasing the survival of both I. scapularis and A. phagocytophilum at extreme temperatures (Neelakanta et al., 2010).

This study found $D$. variabilis ticks infected with $F$. tularensis had a lower SCP than uninfected ticks $(\mathrm{P}<0.05)$. Given that our data is statistically significant, it is likely the relationship between $F$. tularensis and $D$. variabilis is benefitting $D$. variabilis by decreasing their SCPs which would, in turn, give them the ability to survive lower temperatures. It is possible that the relationship between F. tularensis and D. variabilis has become mutually beneficial over many years of evolution. Further studies should determine whether this is a genetic relationship between the host and bacteria or an internal physiological change (such as increased solutes). This would determine what physiological changes are occurring in $D$. variabilis infected with $F$. tularensis.

\subsection{Infection Influence on Size}

There was no significant difference in the size of ticks infected with $F$. tularensis compared to uninfected ticks ( $\mathrm{p}=0.57$ ). This study showed that $F$. tularensis can be found within Nova Scotia $D$. variabilis ticks; however, the overall infection rate in ticks is low. Of the ticks tested, adult non-engorged female ticks have the highest infection rate. F. tularensis can be found in male and engorged female ticks, but the likelihood of infection is less common. To date, the pathogen-vector relationship between $F$. tularensis and ticks is understudied and there are no convincing data on what type of symbiosis is shared between these two organisms. The current study suggests a relationship between $F$. tularensis and $D$. variabilis ticks where $F$. tularensis helps $D$. variabilis survive lower temperatures. 
Understanding endosymbiont relationships in ticks is essential for mitigation and prevention of diseases. This study contributes to the limited body of knowledge regarding the physiological influences of endosymbionts on ticks. The results suggest that infection with $F$. tularensis does not influence the size of $D$. variabilis; however it affects the SCP of these ticks. In terms of cold hardiness and size, this study suggests that $F$. tularensis may have a mutualistic influence on D. variabilis. In order to confirm these results, further studies should be conducted in order to confirm with a higher sample set. Further examination of the relationships of $D$. variabilis with other bacteria should also be considered in order to better understand how microorganisms affect the physiology of ticks.

\section{Acknowledgment}

We would like to thank all of the people who have made a contribution to this study. We would also like give thanks to all of the veterinarians of Nova Scotia and students of Dalhousie University for their assistance in collecting ticks. Finally, we would like to recognize the Marine Gene Probe Lab at Dalhousie University for allowing access to their lab and equipment for the DNA sequencing portion of this study.

\section{References}

Bale, J. S. (2002). Insects and low temperatures: from molecular biology to distributions and abundance. Philosophical Transactions of the Royal Society B: Biological Sciences, 357(1423), 849-862.

Bell, J. F. (1977). Tularemia. CRC Handbook Series in Zoonoses, Section A (pp. 161-193).

Burks, C. S., STEWART, R. L., Needham, G. R., \& LEE, R. E. (1996). The role of direct chilling injury and inoculative freezing in cold tolerance of Amblyomma americanum, Dermacentor variabilis and Ixodes scapularis. Physiological Entomology, 21(1), 44-50.

Carmichael, J. R., \& Fuerst, P. A. (2006). A rickettsial mixed infection in a Dermacentor variabilis tick from Ohio. Annals of the New York Academy of Sciences, 1078(1), 334-337.

Curry, E., El Nabbout, A., Kho, J., Entremont, K. D., Jacks, F., \& Rossolimo, T. (2017). Effect of Bartonella spp. on the Freezing Tolerance in Female Ixodes scapularis. International Journal of Biology, 9(3), 65. https://doi.org/10.5539/ijb.v9n3p65

Dantel, H., \& Knülle, W. (1996). The supercooling ability of ticks (Acari, Ixodoidea). Journal of Comparative Physiology B, 166(8), 517-524.

Dautel, H., \& Knülle, W. (1997). Cold hardiness, supercooling ability and causes of low-temperature mortality in the soft tick, Argas reflexus, and the hard tick, Ixodes ricinus (Acari: Ixodoidea) from Central Europe. Journal of Insect Physiology, 43(9), 843-854.

Dautel, H., \& Knülle, W. (1998). Seasonal oviposition and temperature requirements of eggs may limit northern distribution of European Argas reflexus (Acari: Argasidae). Journal of medical entomology, 35(1), 26-37.

Dennis, D. T., Inglesby, T. V., Henderson, D. A., Bartlett, J. G., Ascher, M. S., \& Eitzen, E. (2001). For The Working Group on Civilian Biodefense. Tularemia as a Biological Weapon. Jama, 285(21), 2763.

Doucet, D., Walker, V. K., \& Qin, W. (2009). The bugs that came in from the cold: Molecular adaptations to low temperatures in insects. Cellular and Molecular Life Sciences, 66(8), 1404-1418.

Engineering Toolbox. (n.d.). Ethanol Freeze Protected Water Solutions. Retrieved March 21, 2016, from http://www.engineeringtoolbox.com/ethanol-water-d_989.html

Genchi, M., Prati, P., Vicari, N., Manfredini, A., Sacchi, L., Clementi, E., ... \& Fabbi, M. (2015). Francisella tularensis: No evidence for transovarial transmission in the tularemia tick vectors Dermacentor reticulatus and Ixodes ricinus. PloS one, 10(8), e0133593.

Hajdušek, O., Š́ma, R., Ayllón, N., Jalovecká, M., Perner, J., Fuente, J. D., \& Kopáček, P. (2013). Interaction of the tick immune system with transmitted pathogens. Frontiers in Cellular and Infection Microbiology, 3.

Hayes, E. B., Goodman, J. L., Dennis, D. T., \& Sonenshine, D. E. (2005). Tick-borne diseases of humans. Tularemian, 207-217.

Herrmann, C., \& Gern, L. (2010). Survival of Ixodes ricinus (Acari: Ixodidae) Under Challenging Conditions of Temperature and Humidity Is Influenced by Borrelia burgdorferi sensu lato Infection. Journal of Medical Entomology, 47(6), 1196-1204.

Herrmann, C., \& Gern, L. (2012). Do the level of energy reserves, hydration status and Borrelia infection influence walking by Ixodes ricinus (Acari: Ixodidae) ticks? Parasitology, 139(03), 330-337. 
Herrmann, C., Voordouw, M., \& Gern, L. (2013). Ixodes ricinus ticks infected with the causative agent of Lyme disease, Borrelia burgdorferi sensu lato, have higher energy reserves. International Journal for Parasitology, $4(6), 477-483$.

Hopla, C. E. (1974). The ecology of tularemia. Advances in Veterinary Science and Comparative Medicine, 18, $25-53$.

Kopáček, P. (2015). Tick: Innate Immunity. Encyclopedia of Parasitology, 1-4.

Lee, R. E. (1991). Principles of Insect Low Temperature Tolerance. Insects at Low Temperature, 17-46.

Lee, R. E. (2010). A primer on insect cold tolerance. Low Temperature Biology of Insects, 3-34.

Lee, W., Shew, J., Hong, F. D., Sery, T. W., Donoso, L. A., Young, L., \& Lee, E. Y. (1987). The retinoblastoma susceptibility gene encodes a nuclear phosphoprotein associated with DNA binding activity. Nature, $329(6140), 642-645$.

Nabbout, A. E., Kho, J., Lloyd, V., \& Rossolimo, T. (2017). Rickettsia spp. and its Effects on the Physiology and Behaviour of Dermacentor Variabilis. International Journal of Biology, 9(2), 39. https://doi.org/10.5539/ ijb.v9n2p39

Needham, G. R., Jaworski, D. C., Chen, C. P., \& Lee, Jr. R. E. (1996). Cold-hardiness of a laboratory colony of Lone Star ticks (Acari: Ixodidae). Journal of Medical Entomology, 33, 706-710.

Neelakanta, G, Sultana, H, Fish, D., Anderson, J. F., \& Fikrig, E. (2010). Anaplasma phagocytophilum induces ixodus scapularis ticks to express an antifreeze glycoprotein gene that enhances their survival in the cold. Journal of Clinical Investigation, 120(9), 3179-3190.

Olsufiev, N. G., \& Khatenever, L. M. (1943). Tularemia infection. Moscow, Russia. Parasitology of tularemia, 74-92.

Petersen, J. M., \& Schriefer, M. E. (2005). Tularemia: Emergence/re-emergence. Journal of Veterinary Research, 36(3), 455-467.

Petersen, J. M., Mead, P. S., \& Schriefer, M. E. (2008). Francisella tularensis: An arthropod-borne pathogen. Journal of Veterinary Research, 40(2), 7.

Petersen, J. M., Schriefer, M. E., Gage, K. L., Montenieri, J. A., Carter, L. G., Stanley, M., \& Chu, M. C. (2004). Methods for enhanced culture recovery of Francisella tularensis. Applied and environmental microbiology, 70(6), 3733-3735. https://doi.org/10.1128/aem.70.6.3733-3735.2004

Petrov, V. G. (1960). Experimental Study of Dermacentor marginatus Sulz. and Rhipicephalus rossicus Jak. et K. Jak. Ticks as Vectors of Tularemia. The Journal of Parasitology, 46(6), 877.

Pincheira-Donoso, D., \& Hunt, J. (2015). Fecundity selection theory: Concepts and evidence. bioRxiv, 1-26.

Reese, S. M., Dietrich, G., Dolan, M. C., Sheldon, S. W., Piesman, J., Petersen, J. M., \& Eisen, R. J. (2010). Transmission Dynamics of Francisella tularensis Subspecies and Clades by Nymphal Dermacentor variabilis (Acari: Ixodidae). American Journal of Tropical Medicine and Hygiene, 83(3), 645-652.

Stark, U., \& Gothe, R. (2000). Studies on the critical water mass, rehydration capability and potential, acute chill tolerance and supercooling point of Argas (Persicargas) walkerae (Acari: Argasidae). Onderstepoort Journal of Veterinary Research.

WHO. (2017). Emergencies preparedness, response: Tularaemia. Retrieved December 30, 2017 from http://www.who.int/csr/delibepidemics/tularaemia/en/

Yu, Z., Lu, Y., Yang, X., Chen, J., Wang, H., Wang, D., \& Liu, J. (2014). Cold hardiness and biochemical response to low temperature of the unfed bush tick Haemaphysalis longicornis (Acari: Ixodidae). Parasites \& Vectors Parasit Vectors, 7(1), 346.

\section{Copyrights}

Copyright for this article is retained by the author(s), with first publication rights granted to the journal.

This is an open-access article distributed under the terms and conditions of the Creative Commons Attribution license (http://creativecommons.org/licenses/by/4.0/). 